\title{
Adversity Quotient Mahasiswa Pendidikan Matematika dan Keterkaitannya dengan Indeks Prestasi Kumulatif
}

\author{
Eva Mulyani ${ }^{*}$, Setya Wahyuningsih ${ }^{2}$, dan Ike Natalliasari ${ }^{3}$ \\ Pendidikan Matematika, Universitas Siliwangi \\ Jalan Siliwangi 24, Kota Tasikmalaya, Indonesia \\ 1*evamulyani@unsil.ac.id \\ ${ }^{2}$ setyawahyuningsih@unsil.ac.id \\ 3ikenatalliasari@unsil.ac.id
}

Artikel diterima: 03-12-2018, direvisi: 29-01-2019, diterbitkan: 31-01-2019

\begin{abstract}
Abstrak
Tujuan penelitian ini adalah untuk mengetahui Adversity quotient mahasiswa pendidikan matematika angkatan 2015 dan mengetahui ada atau tidak adanya keterkaitan antara Adversity quotient dengan Indeks Prestasi Kumulatif (IPK) mahasiswa pendidikan matematika angkatan 2015. Penelitian ini merupakan penelitian deskriftif korelatif. Menggunakan metode korelasional yang tujuannya untuk menyelidiki sejauh mana variasi pada satu variabel berkaitan dengan variabel yang lainnya. Berdasarkan hasil analsis data penelitian, bahwa tingkat Adversity quotient (AQ) mahasiswa jurusan pendidikan matematika FKIP Universitas Siliwangi angkatan 2015 secara umum berada pada kategori $A Q$ sedang (camper). Sebesar $66 \%$ mahasiswa memiliki AQ sedang, dan umumnya memiliki IPK dengan predikat sangat memuaskan. 1 orang mahasiswa memiliki IPK dengan predikat pujian dan memiliki AQ tinggi (climber), 1 orang mahasiswa memiliki IPK dengan predikat pujian namun AQ nya berada pada kategori peralihan dari quitter ke camper, 14 orang mahasiswa memiliki IPK dengan tidak memiliki predikat namun AQ nya sedang (camper), dan 2 orang mahasiswa memiliki IPK dengan tidak memiliki predikat namun AQ nya berada pada kategori peralihan dari camper ke climber. Serta terdapat keterkaitan yang signifikan antara Adversity quotient dengan Indeks Prestasi Kumulatif.

Kata Kunci: Adversity quotient, keterkaitan, IPK.
\end{abstract}

\section{Adversity Quotient of Mathematics Education Students and Its Correlation with Their Grade Point Average}

\section{Abstract}

The purpose of this research was to find out the 2015 adversity quotient of mathematics education students in academic year 2015 and find out whether there was link between Adversity quotient and the 2015 Grade Point Average (GPA) of this students or not. This research was descriptive correlative research. Using a correlational method which aims to investigate to what extent variations on one variable are related to the other variables. Based on the results of research data analysis, the level of Adversity quotient students majoring in mathematics education FKIP Siliwangi University class of 2015 in general is in the category of moderate $A Q$ (camper). More precisely $66 \%$ of students have moderate $A Q$, and generally have a very satisfying GPA. One student has a GPA with a predicate of praise and has a high $A Q$ (climber), one student has IPK with the title of praise but the $A Q$ is in the transition category from quitter to camper, 14 students have GPA with no predicate but the $A Q$ is camper, and two students have IPK with no predicate but the $A Q$ is in the transition category from camper to climber. There is a significant relationship between Adversity quotient and Grade Point Average.

Keyword: Adversity quotient, relevance, GPA. 


\section{Pendahuluan}

Pengetahuan dan teknologi kian berkembang di awal abad 21, terjadi pula berbagai kemajuan di berbagai bidang ilmu, baik dalam ilmu pengetahuan maupun teknologi. Berbagai perubahan dan permasalahan yang terjadi diantaranya yaitu di bidang perekonomian, keuangan, politik, sosial, industri, sumber daya alam, dan tuntutan kerja. Oleh karena itu, diperlukan suatu kemampuan dan kegigihan menghadapi berbagai rintangan dengan terus belajar dan semangat untuk terus mengembangkan diri guna mengatasi berbagai permasalahan dan kesulitan dampak dari perubahan tersebut serta mampu berprestasi dalam bidangnya masingmasing.

Prestasi merupakan hasil dari sebuah usaha yang dilakukan secara kontinu dan memerlukan kecerdasan intelektual, emosional dan juga spiritual. Dalam prosesnya, untuk mendapatkan sebuah prestasi seorang mahasiswa harus melalui proses belajar. Pengalaman-pengalaman tersebut tentunya melibatkan kecerdasan berpikir juga kemampuan mengatasi berbagai masalah dan kegigihan berjuang untuk memperoleh hasil/prestasi yang maksimal. Kegigihan tersebut tentunya merupakan kemampuan yang didorong dari dalam diri seseorang yang disebut sebagai Adversity quotient.

Adversity quotient merupakan kecerdasan yang dimiliki seseorang ketika menghadapi permasalahan, atau bisa dikatakan merupakan kecerdasan daya juang seseorang. Stoltz (2000) mengelompokkan orang kedalam tiga kategori $A Q$, yaitu quitter, camper dan climber. Stoltz juga mengungkapkan bahwa seseorang yang memiliki Adversity quotient yang tinggi akan selalu berusaha dalam menyelesaikan tugas yang diberikan meskipun menemukan kesulitan. Sedangkan seseorang yang memiliki kecerdasan Adversity quotient yang rendah akan berhenti menyelesaikan tugas yang diberikan ketika menemui kesulitan. Untuk mengetahui tingkat kecerdasan Adversity quotient peserta didik dapat dilakukan dengan menggunakan angket adversity response profile.

Adversity Response Profile merupakan instrumen yang valid yang dapat digunakan untuk mungukur respons mahasiswa dalam menghadapi kesulitan. Sebagaimana yang dikatakan oleh Stoltz (2000) bahwa adversity response profile telah digunakan oleh lebih dari 7.500 orang di seluruh dunia dari berbagai karier, usia, ras dan budaya, bahkan digunakan untuk penelitian di berbagai perusahaan dan sekolah. Angket ini akan diberikan kepada mahasiswa pendidikan matematika untuk mengetahui apakah mahasiswa tersebut termasuk kategori quitter ( $\mathrm{AQ}$ rendah), camper ( $\mathrm{AQ}$ sedang) dan climber (AQ tinggi).

Berdasarkan uraian dan permasalahan yang telah diungkapkan di atas, peneliti menduga ada keterkaitan antara Adversity quotient dengan prestasi akademik mahasiswa jurusan pendidikan

Mosharafa: Jumal Pendidikan Matematika Volume 8, Nomor 1, Januari 2019 Copyright $\odot 2019$ Mosharafa: Jurnal Pendidikan Matematika 
matematika FKIP Universitas Siliwangi, namun hal ini perlu dilakukan penelitian agar bisa terbukti kebenarannya.

Berdasarkan latar belakang masalah yang telah dikemukakan sebelumnya, maka masalah dalam penelitian ini dirumuskan sebagai berikut, Bagaimanakah Adversity quotient mahasiswa pendidikan matematika angkatan 2015, dan adakah keterkaitan antara Adversity Qouotient dengan indeks prestasi kumulatif mahasiswa pendidikan matematika angkatan 2015?

Hipotesis yang akan diuji dalam penelitian ini adalah "Ada keterkaitan antara Adversity quotient dengan Indeks Prestasi Kumulatif mahasiswa pendidikan matematika angkatan 2015" dengan pertanyaan penelitian "Bagaimanakah Adversity quotient mahasiswa pendidikan matematika angkatan 2015?"

Penelitian ini diharapkan dapat bermanfaat baik secara teoritis maupun praktis, yaitu: a) Bagi mahasiswa, sebagai motivasi untuk meningkatkan prestasi serta semangat dan daya juang dalam menghadapi kesulitan; dan b) Bagi dosen, dapat bermanfaat sebagai bahan masukan dalam mengembangkan kemampuan mendidik serta mengajar dan memotivasi mahasiswa agar Adversity quotient mahasiswa tersebut berada pada kategori baik.

Stoltz (2000) menjelaskan bahwa "Adversity quotient is the capacity of the person to deal with the adversities of his life. Terjemahan dari pendapat tersebut adalah "kemampuan seseorang untuk menghadapi tantangan kesengsaraan dalam hidupnya" (Suhartono, 2016, p. 63). Sehingga dapat dianalogikan bahwa $A Q$ merupakan intelejensi khusus yang berkaitan dengan kemampuan berpikir kreatif dan kritis peserta didik dalam memecahkan masalah.

Stoltz (2000) mengelompokkan orang ke dalam tiga kategori $A Q$, yaitu: quitter ( $A Q$ rendah), camper ( $A Q$ sedang), dan climber ( $A Q$ tinggi). Quitter yaitu seorang yang menyerah ketika menghadapi tantangan. Mereka adalah orang yang berhenti menyelesaikan masalah meskipun permasalahannya belum tuntas karena mereka merasa tidak akan mampu melanjutkan usahanya dalam menyelesaikan masalah. Camper adalah orang yang berada di posisi tertentu. Mereka merasa cukup dengan apa yang diperolehnya, sehingga mereka tidak melanjutkan kembali usahanya sampai maksimal. Climber berarti orang yang akan selalu berusaha menghadapi rintangan, bertahan dalam kesulitan dan menghadapi kesulitan tersebut untuk mencapai tujuan yang diinginkan.

Untuk mengelompokkan orang kedalam tiga kategori tersebut digunakan angket adversity response profile (ARP). Dalam angket adversity response profile (ARP). Ada empat dimensi atau aspek yang biasa disebut CO2RE yaitu: Control (Kontrol), Origin and Ownership (Asal- usul dan Pengakuan), Reach (Jangkauan), Endurance (Daya tahan)". Control merupakan kemampuan individu dalam mengendalikan peristiwa sulit. Adanya

\section{Mosharafa: Jurnal Pendidikan Matematika}

121

Volume 8, Nomor 1, Januari 2019

Copyright @ 2019 Mosharafa: Jurnal Pendidikan Matematika 
kontrol yang baik menjadikan seorang individu mampu untuk mengendalikan situasi yang sulit (Stoltz, 2000, p. 141).

Empat dimensi atau aspek Adversity quotient yang biasa disebut CO2RE yaitu: (a) control yaitu kemampuan individu dalam mengendalikan pesristiwa sulit, (b) Origin and Ownership yaitu kemampuan individu untuk mengakui asal usul timbulnya kesulitan serta kemampuan untuk merespon setelah mengetahui adanya akibat-akibat yang dihadapi, (c) Reach yaitu kemampuan individu untuk memperkecil akibat dari kesulitan agar kesulitan yang dihadapi tidak mempengaruhi sisi lain dari kehidupannya, (d) Endurance yaitu kemampuan individu untuk bertahan dalam kesulitan yang dihadapinya.

Adversity Response Profile memuat 30 cerita peristiwa. Setiap peristiwa disertai dua pernyataan yang menggunakan skala bipolar lima poin. Pernyataan-pernyataan tersebut ada yang bersifat negatif dan juga yang bersifat positif. Ada 40 pernyataan yang bersifat negatif. Stoltz mengatakan bahwa pernyataan negatif inilah yang diperhatikan skornya, karena kita lebih memperhatikan respon-respon terhadap kesulitan.

Kualitas mahasiswa salah satunya dapat dilihat dari prestasi akademik yang diraihnya, dalam hal ini pretasi akademik yang dimaksud adalah nilai IPKnya. Prestasi akademik merupakan tingkah laku atau kemampuan yang dapat bertambah selama beberapa waktu yang tidak disebabkan proses pertumbuhan 122 melainkan diperolehnya melalui belajar sehingga dipandang sebagai bukti usaha mahasiswa. Hal ini sejalan dengan pendapat Suryabrata (2006) yang menyatakan bahwa prestasi akademik hasil belajar terakhir yang dicapai oleh siswa dalam jangka waktu tertentu (p. 56). Prestasi belajar yang diperoleh mahasiswa tiap semester biasanya disebut Indeks Prestasi.

Indeks Prestasi biasa disingkat IP adalah salah satu alat ukur prestasi dibidang akademik/ pendidikan. Meskipun bernama "indeks", IP sebenarnya bukanlah indeks dalam pengertian yang sebenarnya, melainkan semacam rerata terboboti. Pada tingkat pendidikan tinggi IP dihitung sebagai rerata nilai yang diperoleh seorang mahasiswa pada mata kuliah tersebut setelah diberi bobot dengan "angka kredit". Nilai tersebut berkisar antara 4(A, terbaik) sampai 0 ( $E$, gagal/ tidak lulus). IP dihitung setiap semester. Indeks Prestasi kumulatif (IPK) adalah penghitungan IP dengan menggabungkan semua mata kuliah yang telah ditempuh sampai suatu semester tertentu. Hal ini sejalan dengan PERMENRISTEKDIKTI NOMOR 44 (2015) yang menyatakan bahwa hasil penilaian capaian pembelajaran lulusan pada akhir program studi dinyatakan dengan Indeks Prestasi kumulatif (IPK) (p.24).

\section{Metode}

Sugiyono (2015) menyatakan "metode penelitian pada dasarnya merupakan cara ilmiah untuk mendapatkan data dengan tujuan dan kegunaan tertentu" (p. 2). 
Penelitian ini merupakan penelitian deskriftif korelatif. Menggunakan metode korelasional tujuannya untuk menyelidiki sejauh mana variasi pada satu variabel berkaitan dengan variabel yang lainnya. Variabel penelitian menurut Sugiyono (2013: 60) "Variabel penelitian adalah segala sesuatu yang berbentuk apa saja yang ditetapkan oleh peneliti untuk dipelajari sehingga diperoleh informasi tentang hal tersebut, kemudian ditarik kesimpulannya". Dalam penelitian ini terdapat dua variabel yang diamati, yaitu

Variabel bebas : Adversity quotient

(x)

Variabel terikat : Indeks Prestasi Kumulatif (y)

Desain penelitian yang digunakan dalam penelitian ini menurut Sugiyono $(2015$, p.8)

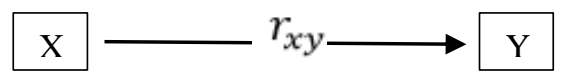

Ket:

$\mathrm{X} \quad$ : Adversity quotient

Y $\quad$ : Indeks Prestasi Kumulatif

$r_{x y}$ : Korelasi Adversity quotient dengan Indeks Prestasi Kumulatif

Sugiyono (2010) populasi adalah wilayah generalisasi yang terdiri atas objek/subjek yang mempunyai kualitas dan karakteristik tertentu yang ditetapkan untuk dipelajari dan kemudian ditarik kesimpulannya. Populasi dalam penelitian ini adalah mahasiswa semester 6 / mahasiswa angkatan 2015 FKIP pendidikan matematika Universitas Siliwangi sebanyak 219 orang.

Mosharafa: Jumal Pendidikan Matematika

Volume 8, Nomor 1, Januari 2019

Copyright @ 2019 Mosharafa: Jurnal Pendidikan Matematika
Sampel adalah bagian dari jumlah dan karakteristik yang dimiliki oleh populasi. Bila populasi besar, dan peneliti tidak mungkin mempelajari semua yang ada pada populasi, misalnya karena keterbatasan dana, tenaga, dan waktu maka peneliti dapat menggunakan sampel yang diambil dari populasi itu. Apa yang dipelajari dari sampel, kesimpulannya akan dapat diberlakukan untuk populasi. Untuk itu sampel yang diambil dari populasi harus benar-benar representatif (mewakili) (Sugiyono, 2010). Teknik pengambilan sampel dalam penelitian ini menggunakan teknik sampel acak (probability random), pengambilan sampel dilakukan dengan menggunakan teknik sampling dengan jenis simple random sampling. Menurut Supranto (2008) simple random sampling adalah sampling dimana pemilihan elemen populasi dilakukan sedemikian rupa sehingga setiap elemen tersebut mempunyai kesempatan yang sama untuk terpilih (p. 24). Jumlah sampel minimum yang digunakan menggunakan perhitungan menurut Slovin. Sampel yang digunakan dalam penelitian ini adalah sebanyak 175 orang mahasiswa jurusan pendidikan matematika FKIP universitas Siliwangi angkatan 2015. Tidak ada kesulitan yang berarti ketika mengambil sampel penelitian pada level mahasiswa (Siregar, 2016; Afriansyah, 2017; Irfan, dkk., 2018), dikarenakan banyak peneltian yang meneliti pada level ini dalam tiga tahun terakhir.

Instrumen penelitian menurut Sugiyono (2013) berpendapat, "Pada prinsipnya 123 
meneliti adalah melakukan pengukuran, maka harus ada alat ukur yang baik. Alat ukur dalam penelitian biasanya dinamakan instrumen penelitian". (p. 148). Instrumen yang digunakan dalam penelitian ini berupa skala Adversity quotient. Skala Adversity quotient yang digunakan diadopsi dari skala adversity response profile (ARP) dari Stoltz yang sudah valid yang terdiri dari dimensi-dimensi quotient yaitu control (pengendalian), origin dan ownership (asal usul dan pengakuan), Reach (jangkauan), dan endurance (daya tahan).

Beberapa teknik pengumpulan data yang digunakan untuk memperoleh data dalam penelitian ini adalah:

\section{a. Angket Adversity quotient}

Menurut Ruseffendi

(2010)

menyatakan "angket adalah sekumpulan pernyataaan atau pertanyaan yang harus dilengkapi oleh responden dengan memilih jawaban atau menjawab pertanyaan melalui jawaban yang sudah disediakan atau melengkapi kalimat dengan jalan mengisi" (p.121). Menurut Sugiyono (2015) berpendapat bahwa kuesioner (angket) merupakan teknik pengumpulan data yang dilakukan dengan cara memberi seperangkat pertanyaan atau pernyataan tertulis kepada responden untuk dijawabnya (p. 142). Jenis angket Adversity quotient diadopsi dari desain angket Adversity quotient Paul G Stolz dalam buku Adversity quotient (2000).

Mengukur seberapa besar ukuran Adversity quotient digunakan instrumen
Adversity quotient dengan menggunakan unsur dimensi Adversity quotient yaitu (CO2RE) seperti yang dilakukan oleh Paul G Stoltz (2000: 140). Dalam angket Adversity quotient terdapat sejumlah pertanyaan yang kemudian dikelompokkan kedalam dimensi control $(C)$, origin (OR) dan ownership $(\mathrm{Ow})$, reach $(\mathrm{R})$, dan endurance $(E)$, atau dengan akronim CO2RE. Angket ini digunakan untuk mengelompokkan mahasiswa kedalam tiga kategori $A Q$ yaitu $A Q$ tinggi (climber), $A Q$ sedang (camper), dan $A Q$ rendah (quitter).

Tabel 1.

Kategori Adversity quotient

\begin{tabular}{ll}
\hline Skor & \multicolumn{1}{c}{ Kategori } \\
\hline$\leq 59$ & Quitter \\
\hline $60-94$ & Peralihan Quitter Ke Camper \\
\hline $95-134$ & Camper \\
\hline $135-165$ & Peralihan Camper Ke Climber \\
\hline$\geq 166$ & Climber \\
\hline
\end{tabular}

b. Pengukuran Indeks Prestasi Kumulatif

Penulis menggunakan teknik dokumentasi terhadap transkip nilai mahasiswa Pendidikan Matematika FKIP Universitas Siliwangi angkatan 2015 untuk mengungkap Indeks Prestasi Kumulatif dalam penelitian ini. Pengukuran berdasarkan predikat lulus ditentukan ditentuka sesuai IPK Mahasiswa. Peraturan Rektor Universitas Siliwangi Nomor 1 (2018) Predikat kelulusan program diploma dan program sarjana adalah sebagai berikut:

2,76-3,00 Memuaskan

3,01 - 3,50 Sangat memuaskan

$>3,50 \quad$ Pujian (p.17) 
Data yang diperoleh akan dianalisis untuk mendapatkan suatu kesimpulan dari penelitian ini. Teknik analisis data yang digunakan dalam penelitian ini adalah dengan menggunakan korelasi product moment dari pearson untuk mengetahui keterkaitan antara Adversity quotient dengan Indeks Prestasi Kumulatif (IPK). Pengolahan data dalam penelitian ini menggunakan analisa statistik dengan dibantu program IBM SPSS 21 for windows yaitu:

\section{a. Deskripsi Data}

Deskripsi data digunakan untuk mengetahui gambaran umum responden. Ananlisis deskriptif memberikan informasi mengenai sekumpulan data dan mendapatkan gagasan untuk keperluan analisis kategorisasi dengan mencari mean, median, modus, dll.

\section{b. Uji Hipotesis}

Pengujian hipotesis dilakukan untuk menjawab pertanyaan utama dari penelitian ini yaitu adakah keterkaitan antara Adversity quotient dengan indeks prestasi kumulatif mahasiswa jurusan pendidikan matematika angkatan 2015 dengan menggunakan Pearson correlation. Perhitungannya menggunakan sistem komputerisasi program IBM SPSS versi 21 yang akan di interpretasikan mengacu pada tabel koefisien korelasi.

\section{Hasil dan Pembahasan}

\section{A. Deskripsi Hasil}

Berikut ini adalah data hasil Adversity Quotient dengan Indeks Prestasi Kumulatif mahasiswa pendidikan matematika.

Tabel 2.

Data $A Q$ dan IPK

\begin{tabular}{lcccc}
\hline Kategori $A Q$ & \multicolumn{4}{c}{ Predikat Kelulusan } \\
\cline { 2 - 5 } & $\begin{array}{c}\text { Tidak memiliki } \\
\text { predikat }\end{array}$ & $\begin{array}{c}\text { memuaskan }(2,76- \\
3,00)\end{array}$ & $\begin{array}{c}\text { Sangat memuaskan } \\
\text { Tidak memiliki } \\
\text { predikat }\end{array}$ \\
\hline Quitter & 0 & 0 & 0 & 0 \\
\hline $\begin{array}{l}\text { Peralihan quitter } \\
\text { ke camper }\end{array}$ & 0 & 0 & 1 & 1 \\
\hline Camper & 14 & 20 & 38 & 10 \\
\hline $\begin{array}{l}\text { Peralihan camper } \\
\text { ke climber }\end{array}$ & 2 & 6 & 1 & 1 \\
\hline Climber & 0 & 0 & & 0 \\
\hline
\end{tabular}

Berdasarkan tabel 2 terlihat bahwa sedang tapi IPK nya tidak memiliki mahasiswa jurusan pendidikan predikat. matematika FKIP Universitas Siliwangi Tabel 3. angkartan 2015 secara umum memiliki $A Q$ sedang (camper) dengan IPK sangat memuaskan yaitu berada pada rentang 3,01-3,50. Meskipun ada yang $A Q$ nya

\section{Mosharafa: Jumal Pendidikan Matematika} Hasil perolehan skor Adversity Respon Profile

\begin{tabular}{ccc}
\hline Skor & Kategori & Frekuensi \\
\hline$\leq 59$ & Quitter & 0 \\
\hline $60-94$ & $\begin{array}{c}\text { Peralihan quitter ke } \\
\text { camper }\end{array}$ & 2 \\
& & \\
\hline
\end{tabular}




\begin{tabular}{|ccc|}
\hline 95-134 & Camper & 115 \\
\hline $135-165$ & $\begin{array}{c}\text { Peralihan camper ke } \\
\text { climber }\end{array}$ & 56 \\
\hline$\geq 166$ & Climber & 2 \\
\hline & Jumlah & 175 \\
\hline
\end{tabular}

Berdasarkan data hasil penelitian diperoleh bahwa tidak terdapat mahasiswa dalam kategori quitter. Dan $A Q$ mahasiswa jurusan pendidikan matematika angkatan 2015 FKIP Universitas Siliwangi secara garis besar berada pada kategori camper. Hal ini terlihat dari Tabel 2 dan secara perhitungan keseleruhan rata-rata skor $A Q$ nya yaitu sebesar 129,29, dan skor tersebut berada pada rentang 95-135 termasuk yang memiliki $A Q$ sedang (camper).

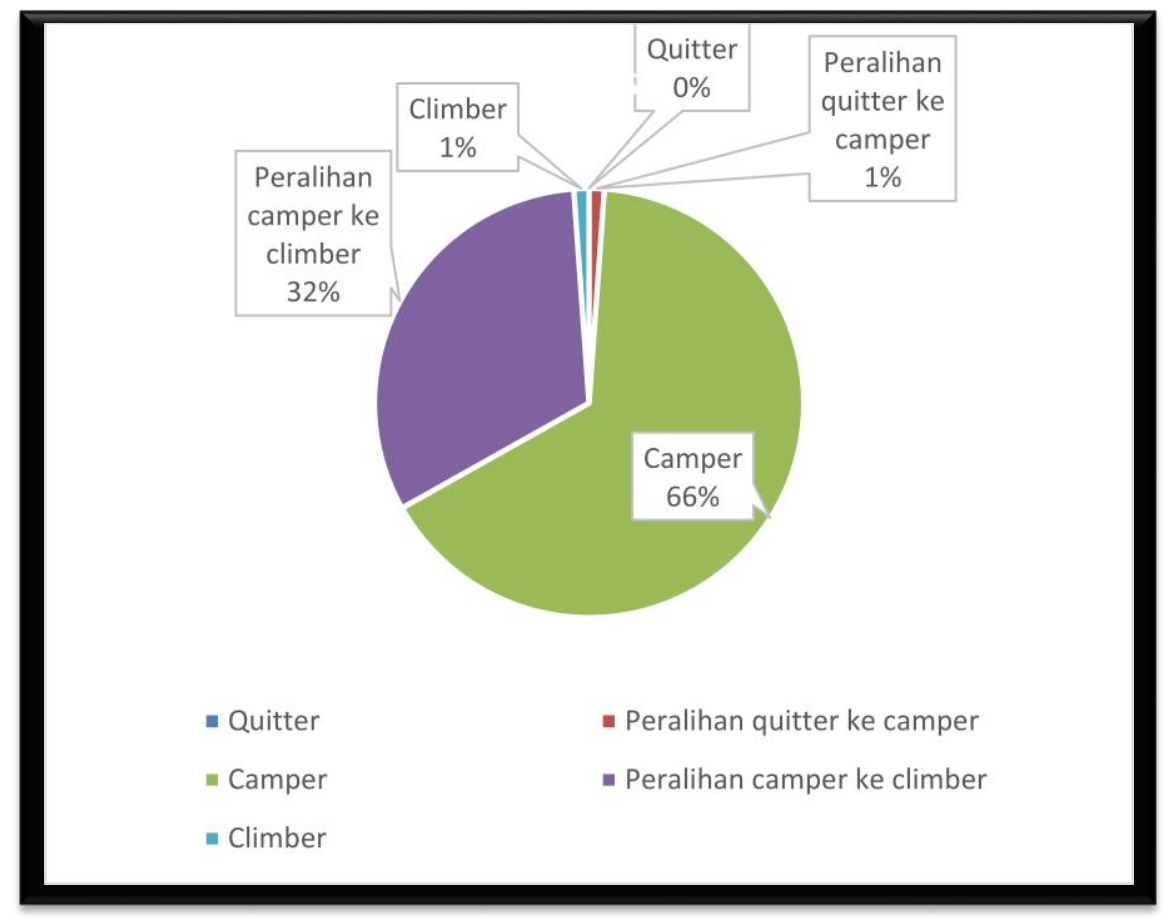

Gambar 1. Diagram kategori mahasiswa berdasarkan $A Q$.

Hasil uji hipotesis pada penelitian ini diperoleh dari perhitungan uji korelasi product momen Person menggunakan program IBM SPSS versi 21. Uji prasyarat yang harus dipenuhi dalam penelitian ini adalah uji normalitas dan linearitas sebelum melakukan uji hipotesis. Berdasarkan perhitungan statistik menunjukkan bahwa kedua variabel berdistribusi normal dan terdapat 126 hubungan linier secara signifikan antara Adversity quotient dengan IPK mahasiswa.

Tahap selanjutnya melakukan uji hipotesis. Berdasarkan perhitungan statistik diperoleh nilai signifikansi 0,032 kurang dari 0,05 maka dapat disimpulkan bahwa terdapat keterkaitan yang signifikan antara Adversity quotient dengan IPK mahasiswa jurusan pendidikan matematika FKIP Universitas Siliwangi Mosharafa: Jumal Pendidikan Matematika Volume 8, Nomor 1, Januari 2019 Copyright $\odot 2019$ Mosharafa: Jurnal Pendidikan Matematika 
angkatan 2015, sehingga hipotesis peneliti diterima. Selain itu diperoleh juga koefisien korelasi pearson sebesar 0,163. Nilai $r$ yang positif menunjukkan bahwa arah hubungan kedua variabel bernilai positif .

\section{B. Pembahasan}

Berdasarkan hasil analsis data penelitian yang sudah diungkapkan sebelumnya, dan mengingat kembali salah satu tujuan dari penelitian ini adalah untuk mengetahui adversity quotient, maka dapat disimpulkan bahwa tingkat Adversity quotient mahasiswa jurusan pendidikan matematika FKIP Universitas Siliwangi angkatan 2015 secara umum berada pada kategori $A Q$ sedang (camper). Lebih tepatnya sebesar $66 \%$ mahasiswa memiliki AQ sedang, dan umumnya memiliki IPK dengan predikat sangat memuaskan. Namun ada pula mahasiswa yang tidak memiliki predikat dengan AQ camper. Hal ini menunjukkan bahwa mahasiswa tersebut memiliki keinginan kuat untuk belajar namun hasilnya tidak sesuai dengan yang diharapkan.

AQ yang dimiliki mahasiswa menunjukkan kemampuannya dalam mengatasi kesulitan/ hambatan yang dialaminya pada masa perkuliahan baik itu dalam mengerjakan tugas individual, tugas kelompok, tugas praktikum, ujian, ataupun gabungan dari semuanya, menjadi dasar atas keberhasilan mencapai IPK yang sesuai dengan yang diharapkannya.

Dari hasil tabulasi diperoleh bahwa 1 orang mahasiswa memiliki IPK dengan predikat pujian dan memiliki $\mathrm{AQ}$ tinggi (climber),1 orang mahasiswa memiliki IPK dengan predikat pujian namun $A Q$ nya berada pada kategori peralihan dari quitter ke camper, 14 orang mahasiswa memiliki IPK dengan tidak memiliki predikat namun AQ nya sedang (camper), dan 2 orang mahasiswa memiliki IPK dengan tidak memiliki predikat namun $A Q$ nya berada pada kategori peralihan dari camper ke climber. Beruntung mahasiswa di jurusan pendidikan matematika FKIP Universitas Siliwangi angkatan 2015 tidak ada yang memiliki AQ rendah (quitter), karena mereka yang memiliki $\mathrm{AQ}$ rendah cenderung merasa puas dengan apa yang mereka dapatkan. Termasuk dalam memperoleh IPK, meskipun IPK yang dimiliki rendah mereka memilih berhenti berusaha untuk meningkatkan IPK yang diperoleh. Seperti yang telah diungkapkan sebelumnya bahwa secara umum AQ yang dimiliki oleh mahasiswa jurusan pendidikan matematika FKIP UNSIL termasuk kategori AQ sedang (camper) dan memiliki IPK pada predikat sangat memuaskan. Apabila dianalisis sesuai dengan CO2RE (control, origin, ownership, reach, endurance) bahwa mahasiswa dengan $\mathrm{AQ}$ sedang (camper) memiliki kendali dan mengelola sebuah kesulitan di masa mendatang, memiliki harapan dan idealitas individu untuk tetap berusaha keras mewujudkan keinginannya walaupun sesulit apapun keadaannya sekarang. Memiliki kemampuan bahwa rasa bersalah yang tepat akan menggugah mahasiswa untuk bertindak dengan benar. 
Menghadapi sebuah kesulitan yang mahasiswa hadapi, dan tidak merambah ke kehidupannya.

Tujuan yang lain dari penelitian ini adalah untuk mengetahui ada atau tidak adanya keterkaitan antara adversity quotient dengan IPK. Berdasarkan hasil analisis data maka diperoleh kesimpulan bahwa terdapat keterkaitan yang positif antara Adversity quotient dengan Indeks Prestasi Kumulatif (IPK). Secara garis besar semakin tinggi Adversity Quotient mahasiswa maka semakin tinggi pula indeks prestasi kumulatifnya.

Berdasarkan hasil wawancara dengan beberapa mahasiswa yang memiliki $A Q$ sedang (camper) mereka merasa senang dengan apa yang sudah ada dan sudah mereka miliki. Mereka mengorbankan kemungkinan yang ada, melepaskan kesempatan untuk maju, tidak mau keluar dari zona nyaman, dan tidak mau mengembangkan diri. Mereka tidak ingin mengambil resiko apabila mereka mengulang mata kuliah, mereka takut usaha yang dilakukan tidak sesuai dengan yang diharapkan. Hal ini sejalan dengan pendapat Stoltz (2000: 19) mengatakan bahwa karena bosan, mereka mengakhiri penda-kiannya dan mencari tempat datar yang rata dan nyaman sebagai tempat bersembunyi dari situasi yang tidak bersahabat. Para mahasiswa yang ada pada kelompok ini cukup baik dalam menempuh perjalanan hidupnya sepanjang segala sesuatunya berjalan lancar. Tipe campers sebenarnya bisa menunjukkan inisiatif dan beberapa usaha 128 untuk mencapai tujuan mereka. Mereka akan berusaha dalam hal apapun yang bisa membuat mereka merasa lebih aman dibandingkan dengan yang telah mereka miliki. Namun para mahasiswa ini banyak mengalami kemunduran pada saat menghadapi hambatan/kesulitan. Misalnya pada saat mereka diberikan tugas perkuliahan yang dirasa berat, mereka akan meninggalkan tugas tersebut karena merasa putus asa, tetapi pada akhirnya tugas yang diberikan dosen tetap selesai walaupun kurang memuaskan atau kurang sempurna. Jadi dapat disimpulkan seseorang yang memiliki AQ tinggi akan lebih mudah dalam meraih prestasi yang lebih baik dari pada seseorang dengan $A Q$ rendah. Hal ini sejalan dengan pendapat Sudarman (2012) yang mengatakan bahwa seseorang yang mempunyai daya tahan yang tinggi akan memiliki harapan dan sikap optimis dalam mengatasi kesulitan atau tantangan yang sedang dihadapi (p.56). Akan tetapi, apabila semakin lama campers berada pada lingkup yang sama maka dikhawatirkan akan timbul perasaan bahwa mereka akan semakin terancam/tersaingi oleh orang yang semakin meningkat prestasinya. Hal ini bisa menyebabkan campers menjadi semakin lamban dan lemah hingga akhirnya mereka akan menjadi quitter. Hal ini sejalan dengan pendapat bahwa camper tidak memanfaatkan potensi mereka sepenuhnya sehingga cenderung kurang berhasil dlam belajar, tumbuh, dan berprestasi (Stoltz, 2007). 


\section{Penutup}

Berdasarkan hasil penelitian dan pembahasan yang sudah dikemukakan maka dapat disimpulkan bahwa: a) Adversity quotient ( $A Q$ ) mahasiswa Jurusan Pendidikan Matematika FKIP Universitas Siliwangi berada pada rentang skor 89 180. $A Q$ tertinggi (climber) ada 2 orang mahasiswa, $A Q$ terendah (quitter) ada 2 orang mahasiswa. Tetapi secara umum $A Q$ mahasiswa jurusan pendidikan matematika FKIP Universitas_Siliwangi berada pada kategori camper ( $A Q$ sedang); dan b) Terdapat keterkaitan yang signifikan antara Adversity quotient dengan Indeks Prestasi Kumulatif.

Berdasarkan dari simpulan yang diperoleh, maka peneliti menyarankan kepada mahasiswa untuk lebih mengasah bahkan meningkatkan AQ yang dimilikinya. Lebih memandang bahwa kesulitan adalah hal yang harus diatasi dan tetap berpikir positif. Dengan demikian hambatanhambatan dalam perkuliahan akan lebih mudah utuk dilewati dan pada akhirnya IPK akan meningkat. Tenaga pengajar hendaknya memberikan bimbingan yang lebih bagi mahasiswa yang memiliki $A Q$ rendah, agar $\mathrm{AQ}$ mahasiswa meningkat dengan cara memberikan dukungan secara psikologis agar mhsiswa mampu menghadapi berbagai rintangan dan kesulitan dengan usaha dan kerja keras, dan diharapkan prestasi akademiknya juga akan meningkat. Peneliti selanjutnya hendaknya memperhatikan variabel prestasi akademik yang lain selain memperhatikan nilai IPK, misalnya menggunakan nilai salah satu mata kuliah, atau bisa juga dengan melihat pada nilai praktikum.

\section{DAfTAR PUSTAKa}

Afriansyah, E. A. (2017). Desain Lintasan Pembelajaran Pecahan melalui Pendekatan Realistic Mathematics Education. Mosharafa: Jurnal Pendidikan Matematika, 6(3), 463474.

Irfan, A., Anzora, \& Fuadi, T. M. (2018). Analisis Pedagogical Content Knowledge Mahasiswa Calon Guru Pada Program Studi Pendidikan Matematika. Mosharafa: Jurnal Pendidikan Matematika, 7(2), 239250.

Russefendi, E., T. (2010). Dasar-dasar Penelitian Pendidikan dan Bidang Non-Eksakta Lainnya. Indonesian. Bandung: Tarsito.

Siregar, I. (2016). Masalah Pembelajaran Pembuktian Matematika bagi Mahasiswa di Indonesia. Mosharafa: Jurnal Pendidikan Matematika, 5(3), 315-324.

Stoltz, P. G. (2000). Adeversity Quotient Turning Obstacles into Opportunities [Mengubah Hambatan Jadi Peluang]. Hermaya. T. Indonesian. Jakarta: PT. Gramedia Widiasarana Indonesia.

Stoltz, P. G. (2007). Adversity Quotient (Ed. Ke-7). Jakarta: PT. Gramedia Indonesia.

Sudarman. (2012). Adversity quotient: Kajian Kemungkinan 
Pengintegrasiannya dalam

Pembelajaran Matematika. Jurnal

Aksioma vol. 1(1). 55-62.

Sugiyono. (2013). Metode Penelitian

Kuantitatif, Kualitatif dan $R$ \& $D$.

indonesian. Indonesian Bandung:

Alfabeta.

Sugiyono. (2015). Metode Penelitian

Kuantitatif, Kualitatif dan $R$ \& $D$.

indonesian. Indonesian Bandung:

Alfabeta.

Suhartono. (2016). "Adversity quotient Sebagai acuan Guru Dalam Menberikan soal Pemecahan Masalah Matematika. Inovasi. 2(18). 62-70.

\section{Riwayat Hidup PenUlis}

\section{Eva mulyani, M.Pd.}

Lahir di Tasikmalaya, 20 Maret 1983. Staf pengajar di Universitas Siliwangi. Studi S1 Pendidikan Matematika Universitas Siliwangi, Kota Tasikmalaya, lulus tahun (2005); S2 Pendidikan Matematika Universitas Terbuka, UPBJJ UT Bandung, lulus tahun (2014)

\section{Dra. Setya Wahyuningsih, M.Pd.}

Lahir di Yogyakarta, 17 Juli 1956. Staf pengajar di Universitas Siliwangi. Studi S1 menejemen Pendidikan IKIP Negeri Kota Yogyakarta, lulus tahun (1982); S2 Pendidikan kependudukan dan lingkungan hidup, Universitas Siliwangi Kota Tasikmalaya, lulus tahun (2004)

\section{Ike Natalliasari, M.Pd.}

Lahir di Ciamis, 05 Desember 1980. Staf pengajar di Universitas Siliwangi. Studi S1 Pendidikan Matematika Universitas Siliwangi, Kota Tasikmalaya, lulus tahun (2003); S2 Pendidikan Matematika Universitas Terbuka, UPBJJ UT Bandung, lulus tahun (2014). 